\title{
INVENTÁRIO DE BIOMASSA EM UM PLANTIO DE Pinus elliottii Engelm. AOS 23 ANOS DE IDADE NO ESTADO DO PARANÁ, BRASIL
}

Marcos Vinicius Giongo Alves ${ }^{1}$, Henrique Soares Koehler ${ }^{2}$ e Luiz Marcelo Brum Rossi ${ }^{3}$

\section{RESUMO}

O presente trabalho estimou a biomassa aérea de um povoamento de Pinus elliotti. com 23 anos de idade, localizado no municipio de Rio Branco do Sul - PR. Foram avaliadas separadamente a biomassa do fuste, galhos e aciculas. A biomassa seca total estimada è composta por $85 \%$ de fuste, $10 \%$ de galhos e $5 \%$ de acículas. O modelo ajustado para a estimativa de biomassa seca aérea total, em função do diâmetro a altura do peito (DAP), apresentou um coeficiente de determinação $\left(R^{2}\right)$ de 0,91 e erro padrão da estimativa (Sxy) de $11,98 \%$. Dentre os modelos ajustados para estimar as diferentes porções de biomassa na árvore, o que estima a biomassa do fuste foi o que apresentou melhor relação entre biomassa e o diâmetro à altura do peito.

Palavras-Chaves: Reflorestamentos, modelagem, biomassa

\section{ABOVE GROUND BIOMASS QUANTIFICATION IN A 23 YEARS OLD Pinus elliottii Engelm. STAND AT RIO BRANCO DO SUL, STATE OF PARANÁ, BRAZIL}

\section{SUMMARY}

Above ground dry biomass was estimated for a 23 years old Pinus elliottii stand, located at Rio Branco do Sul, State of Paraná, Brazil. Stem, branches and needles dry biomass were estimated separately. The estimated total above ground dry biomass was composed by 85 $\%$ of stem, $10 \%$ of branches and $5 \%$ of needles. The adjusted equation for estimation of total dry biomass as a function of the diameter at breast height (DBH), showed a coefficient of determination $\left(R^{2}\right)$ of 0.91 and a standard error in percentage (Sxy\%) of $11,98 \%$. Among the tested models for estimating the different portions of tree dry biomass as a function of $\mathrm{DBH}$, the stem biomass equation was the one that showed the best results.

Keywords: Planted forests, modeling, biomass

1-Universidad Federal do Paraná - UFPR, Curitiba-PR. Brasil ( malves@creapr.org.br)

2-Universidad Federal do Paraná - UFPR, Curitiva-PR, Brasil ( koehler@ufpr.br)

3-Embrapa Amazõnia Ocidental, Manaus-AM, Brasil ( mrossi@cpaa.embrapa.br) 


\section{INTRODUÇÃO}

O Brasil é o sètimo pais em florestas plantadas do mundo, contando atualmente cerca de 5,2 milhões de hectares. A maior parte da área reflorestada existente no Pais formou-se nas décadas de 1970 e 1980, quando da vigência do programa de incentivos fiscais. Esse instrumento tornou possivel às empresas a execução plantios de florestas em larga escala, contando com um incentivo financeiro, uma vez que podiam abater integralmente do Imposto de Renda as importâncias comprovadamente aplicadas em reflorestamento.

As áreas reflorestadas com o gênero Pinus no Brasil ocupam uma área de 1,8 milhão de hectares, representando cerca $38,6 \%$ dos reflorestamentos existentes no país. Esses reflorestamentos com espécies de rápido crescimento representam uma importante alternativa para a produçāo de matéria-prima da industria florestal brasileira.

Desta forma, a estimativa de biomassa das florestas tem um enorme interesse não só a nivel cientifico como também prático. Conforme Martins (2004), citando Paulo et al. (2002), o conhecimento da biomassa seca existente nos diversos ecossistemas é importante para todo um vasto conjunto de aspectos como a comercialização de produtos, estudos da produtividade do sistema florestal, estudos de fluxos de energia e de nutrientes, estudos da contribuição dos ecossistemas para o ciclo global de carbono, assim como para a avaliação da quantidade de combustiveis no que diz respeito aos incêndios florestais.

Na quantificação de biomassa florestal existe a necessidade do desenvolvimento de estudos na quantificaçāo nos diferentes componentes dos individuos, possibilitando assim um melhor entendimento da distribuição da biomassa nas plantas e nos ecossistema, permitindo um melhor entendimento do fluxo de nutrientes e do armazenamento de carbono pelas florestas. Segundo Watzlawick et al. (2004), estes estudos são trabalhosos, demorados e muito onerosos, podendo ser realizados por meio de métodos diretos ou indiretos. Nos métodos diretos, as árvores são derrubadas e seus componentes são separados e pesados, enquanto que nos métodos indiretos são utilizadas equações matemáticas para realizar as estimativas.

Segundo Salati (1994) os mètodos indiretos vem sendo utilizados para se estimar a biomassa de áreas florestais de grandes extensōes e, dependendo das informaçōes disponiveis, são usadas relações empiricas entre a biomassa e algumas variáveis, sendo comumente utilizadas as variáveis de inventário florestal como DAP, altura e volume, os quais são relacionados com a biomassa de alguma forma.

Desta forma, o presente trabalho teve como objetivo o ajustamento e teste de diferentes modelos matemáticos para estimar biomassa em função de outras variáveis, determinando suas correlaçōes e finalmente quantificando a biomassa seca aérea da área de estudo. 


\section{REVISĀO BIBLIOGRÁFICA}

\&

\section{Os Reflorestamentos no Brasil}

O Brasil é o sétimo pais em termos de área reflorestada no mundo (COFO, 2001), detendo, em 2000, cerca de 5,2 milhões de hectares. Segundo Hoeflich et. al. (2005), no Brasil, a madeira de florestas plantadas, especialmente eucalipto e pino, constituem uma das fontes mais importante de matéria-prima para os diversos usos industriais. As áreas reflorestadas com o gênero Pinus representam aproximadamente $38,6 \%$ dos reflorestamentos nacionais ocupando uma área de aproximadamente 1,8 milhão de hectares, sendo o Estado do Paraná o maior detentor dessas florestas, com uma participação de $36 \%$ do total da área plantada com este gênero no Brasil, conforme observamos na Figura $\mathrm{N}^{*} 1$.

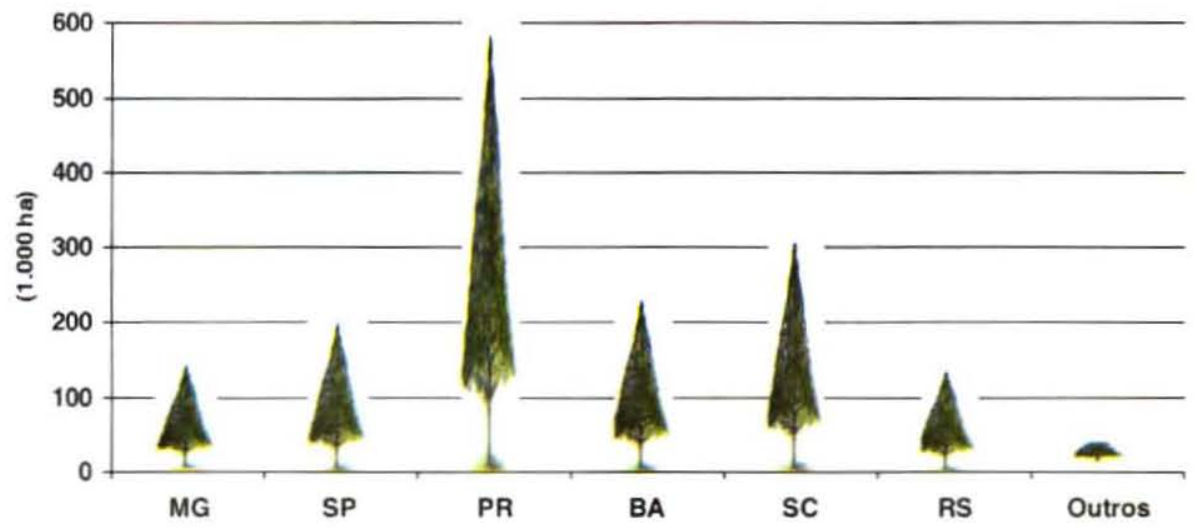

Fonte: SBS (2003)

Figura $N^{\circ} 1$

DISTRIBUIÇĀO DAS FLORESTAS PLANTADAS COM PINUS POR ESTADOS, NO BRASIL

\section{Determinação de Biomassa}

O termo biomassa florestal, conforme Sanquetta (2002), pode significar toda a biomassa existente na floresta ou apenas a fração arbórea da mesma, podendo-se também utilizar o termo fitomassa florestal ou fitomassa arbórea. No que se refere à determinação de biomassa. o mesmo autor comenta que, nos métodos diretos, os procedimentos de campo utilizados na determinaçăo de biomassa de florestas podem variar amplamente, segundo os objetivos e as restriçōes técnicas e orçamentárias. Segundo o autor, os métodos indiretos não podem ser utilizados sem o ajuste e a calibragem prévia de equações, devendo ser empregados conjuntamente com os métodos diretos.

Para Martins (2004), o procedimento comum para a quantificação de biomassa é a 
utilização do recurso de regressão, onde, após a seleção das árvores a serem amostradas, procede-se a derrubada e a determinação da biomassa dos diferentes componentes considerados da árvore. Posteriormente são ajustadas equações de regressão para cada um dos componentes em questão, relacionados às variáveis biométricas das árvores.

\section{MATERIAL E MÉTODO}

\section{Área de Estudo}

A área objeto de estudo deste trabalho está localizada no Estado do Paraná, Municipio de Rio Branco do Sul, distantes 33 km de Curitiba e 124 km do Porto de Paranaguá. A área encontra-se na região Leste do Estado, a 890 m de altitude, $25^{\circ} 10^{\prime} 22^{\prime \prime}$ de latitude S e $49^{\circ} 19^{\prime}$ $10^{\prime \prime}$ de longitude W-GR, conforme observamos na Figura N².

O clima da região é classificado como Cfb, segundo a classificação de Köppen, ou seja, clima subtropical, mesotérmico, sempre úmido, com verões de temperatura branda, geadas freqüentes e sem estação seca. A temperatura dos meses mais quentes é inferior a $22^{\circ} \mathrm{C} e$ dos meses mais frios inferior a $18^{\circ} \mathrm{C}$, com temperatura média anual de $16,5^{\circ} \mathrm{C}$ e apresentando máxima média igual a $22,6^{\circ} \mathrm{C}$. A precipitação pluviométrica anual média varia de $1400 \mathrm{~mm}$ a $1600 \mathrm{~mm}$, sendo que as chuvas são distribuidas em todos os meses do ano, com maior abundância no verăo, nos meses de janeiro e fevereiro e menos freqüentes nos meses de julho e agosto, apresentando uma umidade relativa média de $85 \%$, indice hidrico entre 60 e 100 e sem deficiência hídrica.

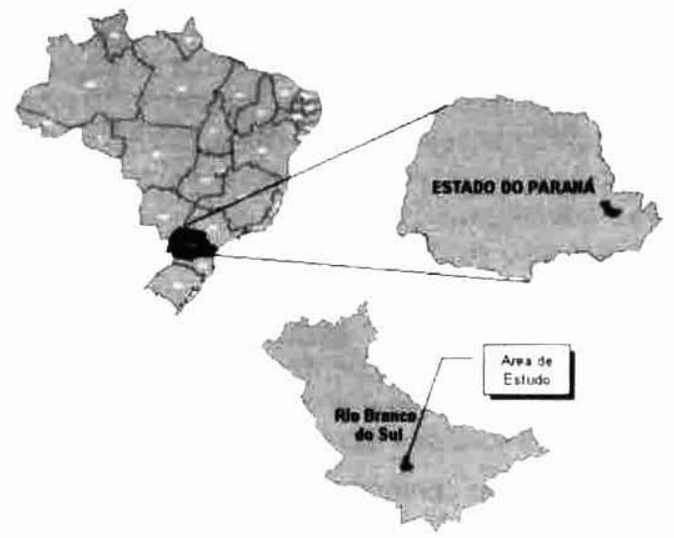

Fonte: Elaborado pelos autores (2006)

\section{Figura $\mathrm{N}^{\circ} 2$ \\ CROQUI DE LOCALIZAÇÃO DA ÁREA OBJETO DE ESTUDO DESTE TRABALHO}

A região apresenta, na maioria de seu território um relevo ondulado e montanhoso com grandes desniveis altimétricos. Os terrenos da região estão assentados predominantemente sobre rochas calcárias, filitos, xistos e quartzitos, os quais têm alta suscetibilidade à dissolução. 
sendo muito comum nessas áreas a presença de dolinas e cavernas, tipicas de terrenos cársticos.

Os solos são produtos da ação do intemperismo sobre as formaçōes geologicas e seu desenvolvimento está diretamente ligado ao tipo de relevo por estas geradas. Destacam-se três tipos de solos: o latossolo vermelho-amarelo de baixa fertilidade natural, onde ocorre o processo de lixiviação muito intensa, conforme o regime de chuvas; o podzólico vermelhoamarelo facilmente erodivel, em funçāo de diferentes condicionantes naturais; e o cambissolo raso drenado e de limitado uso agricola.

\section{Inventário Florestal}

Para a realização do inventário florestal utilizou-se o processo de amostragem sistemático, ou seja, as unidades foram distribuidas sistematicamente em linha na área inventariada. Cada unidade de amostra (UA) foi alocada a uma distância de pelo menos trinta metros (30 m) da bordadura dos limites, evitando-se assim a inclusāo de árvores de bordadura.

O método de amostragem utilizado foi o da área fixa devido à praticidade e sua simplicidade no estabelecimento das unidades amostrais no campo, conforme Péllico Netto e Brena (1997). Nesse método de amostragem a medição das árvores é feita dentro da unidade de amostra, considerando por conseqüência a freqüência de individuos que nela ocorrem.
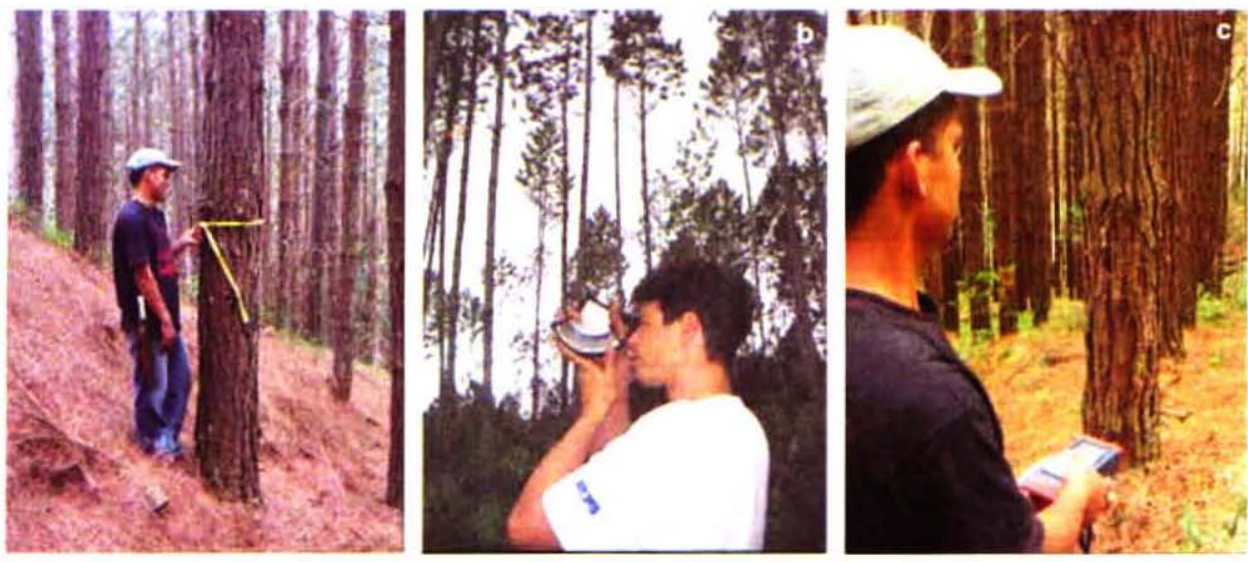

Figura $\mathrm{N}^{\circ} 3$

INVENTÁRIO FLORESTA (A) MEDIÇĀO DA CIRCUNFERÊNCIA À ALTURA DO PEITO (CAP) COM A UTILIZAÇÃO DE FITA MÉTRICA, (B) MEDIÇÃO DE ALTURA DAS ÁRVORES COM HIPSÔMETRO DE BLUME-LEISS E (C) DETERMINAÇÄO DOS LIMITES DA PARCELA COM A UTILIZAÇÃO DE UM DISTANCIÔMETRO 


\section{Determinação da Biomassa}

Com base nos dados obtidos no inventário florestal foi elaborada a distribuição da freqüência dos diâmetros em seis classes diâmetricas, tendo sido abatidas 23 árvores, distribuidas proporcionalmente entre as classes de diâmetros definidas.

Após a determinação dos números de árvores a serem abatidas por classe de diâmetro, as mesmas foram selecionadas nos levantamentos de campo de forma aleatória, onde se realizou a quantificação da biomassa nos três componentes previamente definidos: i) fuste, ii) galhos e iii) aciculas conforme observamos na Figura $N^{\circ} 4$.

Antes do abate das árvores, foram coletadas com a utilização de GPS as coordenadas geográficas das mesmas, a circunferência à altura do peito e na base da árvore. A seguir as mesmas foram abatidas e, para facilitar a pesagem, o fuste e os galhos foram secionadas em porções menores.
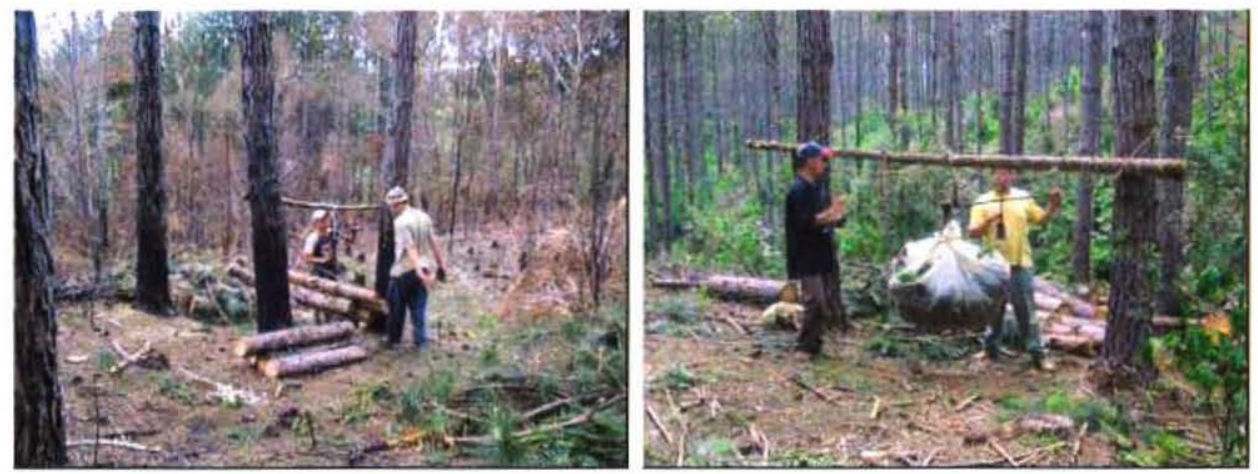

Figura $\mathrm{N}^{\circ} 4$

LEVANTAMENTOS DE CAMPO PARA A QUANTIFICAÇÃO DE BIOMASSA FLORESTA DOS COMPONENTES FUSTE, GALHOS E ACICULAS

\section{RESULTADOS}

Os principais resultados obtidos do inventario florestal realizado na área de estudo podem ser observados na Tabela $\mathrm{N}^{\circ} 1$. 


\section{Tabela $N^{\circ} 1$ \\ VARIÁVEIS DENDROMÉTRICAS RESULTANTES DO INVENTÁRIO FLORESTAL REALIZADO NA ÁREA DE ESTUDO}

\begin{tabular}{|l|c|}
\hline \multicolumn{1}{|c|}{ VARIÁVEIS } & VALORES \\
\hline DAP médio & $28,41 \mathrm{~cm}$ \\
\hline Altura média & $23,70 \mathrm{~m}$ \\
\hline Altura dominante & $24,83 \mathrm{~m}$ \\
\hline Area basal média & $28,82 \mathrm{~m}^{2} \mathrm{ha}^{-1}$ \\
\hline Volume com casca & $359,55 \mathrm{~m}^{3} \mathrm{ha}^{-1}$ \\
\hline Volume sem casca & $309,66 \mathrm{~m}^{3} \mathrm{ha}^{-1}$ \\
\hline Densidade & 444 árvores ha-1 $^{-1}$ \\
\hline
\end{tabular}

$\mathrm{Na}$ Tabela $\mathrm{N}^{\circ} 2$ pode-se observar os resultados da quantificação de biomassa florestal seca aérea nos três componentes avaliados (fuste, galhos e acículas). O componente fuste representa cerca de $85 \%$ do total de biomassa seca dos componentes avaliados, seguido dos galhos com uma participação de $10 \%$ e finalmente as acículas com $5 \%$.

\section{Tabela $N^{\circ} 2$}

BIOMASSA SECA AÉREA DOS DIFERENTES COMPONENTES ANALISADOS

\begin{tabular}{|l|c|}
\hline \multicolumn{1}{|c|}{ COMPONENTE } & $\begin{array}{c}\text { BIOMASSA SECA } \\
\text { (Mg ha-1) }\end{array}$ \\
\hline Fuste & 131,0 \\
\hline Galhos & 15,8 \\
\hline Acículas & 7,7 \\
\hline Biomassa total (aérea) & 161,32 \\
\hline
\end{tabular}

Cabe-se ressaltar que a soma da biomassa dos três componentes avaliados é diferente do total apresentado na Tabela $\mathrm{N}^{\circ} 2$, ou seja, caso sejam somados os três componentes não será obtido o mesmo resultado da biomassa seca total (aérea) de $161,32 \mathrm{Mg} \mathrm{ha}^{-1}$, mas sim $154,50 \mathrm{Mg} \mathrm{ha}^{-1}$. Esta diferença se deve ao fato de se tratarem de estimativas individuais de cada um dos componentes e também da biomassa seca total.

Para a quantificação de biomassa seca da área de estudo, foram ajustados modelos matemáticos lineares, conforme pode-se observar na Tabela $\mathrm{N}^{\circ} 3$, que mostra os modelos que apresentaram melhores resultados, com seus respectivos coeficientes de determinação ajustados e o erro padrão da estimativa. 
Tabela $\mathrm{N}^{\circ} 3$

EQUAÇŌES UTILIZADAS PARA A ESTIMATIVA DE BIOMASSA NOS DIFERENTES COMPONENTES ANALISADOS

\begin{tabular}{|c|c|c|c|c|c|c|c|c|}
\hline \multirow{2}{*}{ MODELO } & \multicolumn{2}{|c|}{ FUSTE } & \multicolumn{2}{|c|}{ GALHOS } & \multicolumn{2}{|c|}{ ACÍCULAS } & \multicolumn{2}{|c|}{$\begin{array}{l}\text { MASSA } \\
\text { TOTAL }\end{array}$} \\
\hline & $\mathbf{R}^{2(1)}$ & $S_{x y}^{(2)}$ & $\mathbf{R}^{2(1)}$ & $S_{x y}^{(2)}$ & $\mathbf{R}^{2(1)}$ & $S_{x y}(2)$ & $\mathbf{R}^{2(1)}$ & $S_{x y}{ }^{(2)}$ \\
\hline$B=b_{0}+b_{1} \cdot$ DAP & 0,81 & 15,35 & 0,71 & 51,46 & 0,71 & 34,71 & 0,85 & 15,58 \\
\hline$B=b_{0}+b_{1} \cdot D A^{2}$ & 0,80 & 15,73 & 0,80 & 43,11 & 0,73 & 33,46 & 0,86 & 14,89 \\
\hline$B=b_{0}+b_{1} \cdot$ DAP.Ht & 0,85 & 19,67 & 0,45 & 71,26 & 0,47 & 46,48 & 0,80 & 18,27 \\
\hline$B=b_{0}+b_{1} \cdot D A P^{2} \cdot H t$ & 0,90 & 11,14 & 0,70 & 53,06 & 0,66 & 37,13 & 0,91 & 11,98 \\
\hline $\begin{array}{l}B=b_{0}+b_{1} \cdot D A P+ \\
b_{2} \cdot D A P^{2}+b_{3} \cdot D A P^{3}\end{array}$ & 0,80 & 15,76 & 0,92 & 26,46 & 0,80 & 28,37 & 0,85 & 15,49 \\
\hline
\end{tabular}

(1) Coeficiente de determinação ajustado ${ }^{(2)}$ Erro padrāo da estimativa

\section{CONCLUSÕES}

Os modelos lineares simples foram os que apresentaram melhores ajustes para a estimativa da biomassa seca do fuste e massa seca total, em quando que para as estimativas de biomassa seca de galhos e aciculas os modeles lineares múltiplos apresentaram os melhores ajustes.

O modelo selecionado para a quantificação de biomassa seca do fuste e total foi $B=b_{0}$ $+b_{1} \cdot D_{A} P^{2} \cdot H t$, apresentado um ajuste satisfatório, para ambos os casos $\left(R^{2}>0,90\right)$. Cabe ainda ressaltar, que a utilização da variável DAP isolada para a estimativa de biomassa seca destes componentes apresentou ajustes que podem ser considerados bons, dada a simplicidade do modelo. Assim, em situaçōes em que a variável altura não é conhecida ou não pode ser estimada, esses modelos podem ser ajustados considerando somente a variável DAP.

Para os componentes galhos e aciculas, a qualidade do ajuste foi inferior quando comparados aos modelos ajustados para fuste e massa total. Isso deve-se ao fato dessas variáveis apresentarem menor correlação com a biomassa. Acredita-se que estes componentes poderiam apresentar melhores ajustes caso fosse considerada a altura de copa. Para estes componentes foi selecionado o modelo $B=b_{0}+b_{1} \cdot D A P+b_{2} \cdot D A P^{2}+b_{3} \cdot D A P^{3}$.

Outro aspecto importante é o fato de que a análise por compartimentos estimou a biomassa seca aérea de $154,50 \mathrm{Mg} \mathrm{ha}^{-1}$ enquanto que o modelo para massa seca total apresentou um resultado de $161,32 \mathrm{Mg} \mathrm{ha}^{-1}$, representando uma diferença de $6,82 \mathrm{Mg} \mathrm{ha}^{-1}$, ou seja, os modelos por compartimento quando comparados ao modelo de biomassa seca total, apresentaram diferença de estimativa de biomassa de cerca de $4 \%$ a menos. 


\section{REFERÊNCIAS}

COFO, 2001. Committee on Forestry, Food and Agriculture Organization. The Global Forest Resources Assessment 2000: Summary Report. Roma: FAO. 38p.

Hoeflich, V.A., Alves, M.V.G., Koehler, H.S. and Medrado, M.J.S., 2005. The Brazilian Forest Sector: Challenges and strategies for its development. in: XXIII IUFRO World Congress, 2005. Brisbane, Queensland, Australia.

Martins, F.B., Páscoa, M.F.M. e Silva, J.C., 2004. Modelos de estimativa de biomassa para aciculas de Pinus pinaster Aiton. in: $3^{\circ}$ Simpósio Latino-americano sobre Manejo Florestal, 2004, Santa Maria,49-54p.

Pellico Netto, S., Brena, D.A., 1997. Inventário Florestal. Curitiba: Editorado pelos autores, $316 \mathrm{p}$.

Salati, E., 1994. Emissão e seqüestro de $\mathrm{CO}_{2}$ - Uma nova oportunidade de negócios para o Brasil. in: Seminário Emissão e Seqüestro de $\mathrm{CO}_{2}$ - Uma nova oportunidade de negócios para o Brasil. Rio de Janeiro, p. 15-37.

Sanquetta, C.R., 2002. Métodos de determinação de biomassa florestal. in: A Florestas e o Carbono. Curitiba, p. 119-140.

SBS, 2003. Sociedade Brasileira de Silvicultura. Disponivel em <http://www.sbs.org.br>.

Watzlawick, I.F., Koehler, H.S. e Kirchner, F.F., 2004. Estimativa de biomassa e carbono em plantios de Pinus taeda I. Utilizando imagens de satélite IKONOS II. in: $3^{\circ}$ Simpósio Latinoamericano sobre Manejo Florestal, Santa Maria, p. 168-178. 
